GRASAS Y ACEITES 65 (2)

April-June 2014, e019

ISSN-L: 0017-3495

doi: http://dx.doi.org/10.3989/gya.074413

\title{
Characterization of fatty acids, bioactive lipids, and radical scavenging activity of Canterbury bells seed oil
}

\author{
M.F.R. Hassanien ${ }^{\mathrm{a}, \mathrm{b}, \bigotimes}$, H. El-Shamy ${ }^{\mathrm{c}}$ and A.A. Abdel Ghany ${ }^{\mathrm{d}}$ \\ ${ }^{a}$ Agricultural Biochemistry Department, Faculty of Agriculture, Zagazig University, Zagazig 44519, Egypt \\ ${ }^{\mathrm{b}}$ Scientific Research Deanship Umm Al-Qura University, Makkah, Kingdom of Saudi Arabia \\ ${ }^{c}$ Horticulture Department, Faculty of Agriculture, Zagazig University, 44519 Zagazig, Egypt \\ ${ }^{\mathrm{d}}$ Faculty of Technology and Development, Zagazig University, Zagazig 44519, Egypt \\ Corresponding author: hassanienmohamed@yahoo.com
}

Submitted: 11 July 2013; Accepted: 23 December 2013

\begin{abstract}
SUMMARY: The aim of this study was to characterize the chemical composition and radical scavenging activity of Canterbury bells (Campanula medium) seed oil. C. medium seeds contained 9.2\% extractable oil. The lipid classes, fatty acids, phytosterol and tocopherol composition of C. medium seed oil were determined. The amount of neutral lipids in the oil was the highest, followed by glycolipids and phospholipids. Linoleic and oleic were the main fatty acids. $C$. medium oil is characterized by high levels of phytosterols and $\beta$-sitosterol was the main compound. $\beta$-Tocopherol constituted $42.5 \%$ of the total tocopherol content followed by $\gamma$-tocopherol. The radical scavenging activity (RSA) toward 1,1-diphenyl-2-picrylhydrazyl (DPPH) radicals and galvinoxyl radicals of C. medium oil were higher than those of extra virgin olive oil. The diverse potential uses of C. medium oil may make this plant industrially important.
\end{abstract}

KEYWORDS: Campanula medium; Canterbury bells; Fatty acids; Lipid-soluble bioactives; Radical scavenging potential; Seed oil

RESUMEN: Caracterización de ácidos grasos, lípidos bioactivos, y actividad de captación de radicales de aceites de semillas de campanillas de Canterbury. El objetivo de este estudio fue caracterizar la composición química y la actividad de captación de radicales de aceites de semillas de campanillas de Canterbury (Campanula medium). Las semillas de $C$. medium contenían 9,2 \% de aceite extraíble. Se determinó la composición de las diferentes clases de lípidos, ácidos grasos, fitoesteroles y tocoferoles. La cantidad de lípidos neutros en el aceite fue mayoritario, seguido de glicolípidos y fosfolípidos. Linoleico y oleico fueron los ácidos grasos principales. El aceite de $C$. medium se caracteriza por altos niveles de fitoesteroles y $\beta$-sitosterol fue el compuesto principal. $\beta$-tocoferol constituía 42,5\% del contenido total de tocoferol seguido de $\gamma$-tocoferol. La actividad de captación de radicales (RSA) a 1,1-difenil-2- picrilhidrazil (DPPH) y radicales galvinoxil de C. medium fueron superiores a las de aceite de oliva virgen extra. Los diversos usos potenciales de los aceites de $C$. medium pueden hacer que esta planta pueda ser importante industrialmente.

PALABRAS CLAVE: Aceites de semilla; Ácidos grasos; Bioactivos solubles en lípidos; Campanillas de Canterbury; Campanula medium; Poder de captación de radicales

Citation/Cómo citar este artículo: Hassanien MFR, El-Shamy H, Abdel Ghany AA. 2014. Characterization of fatty acids, bioactive lipids, and radical scavenging activity of Canterbury bells seed oil. Grasas Aceites 65 (2): e019. doi: http://dx.doi. org/10.3989/gya.074413

Copyright: (C) 2014 CSIC. This is an open-access article distributed under the terms of the Creative Commons Attribution-Non Commercial (by-nc) Spain 3.0 Licence. 


\section{INTRODUCTION}

The genus Campanula (family Campanulaceae) comprises approximately 300 species. All species are herbaceous, and the name refers to the bell-shaped, blue flowers of the majority of the species. The species are perennials, bi-annuals or annuals (Brandt and Ishimaru, 1998). In addition to their use as ornamental plants, Campanula species are used in traditional medicine to treat various diseases such as tonsillitis, laryngitis, bronchitis, and warts. They possess stimulant properties and are used as emetics; they also possess refreshing, antiallergic, antiphlogistic, antioxidant, spasmolytic, antiviral, and antimicrobial properties. Flavonoids are the most important secondary metabolites of the Campanula genus (Morton, 1977; Rameau, 1989; Okinaka et al., 2003; Touafek et al., 2011; Yildırım, 2013).

Canterbury bells (Campanula medium), also known as the bell flower, is an annual or biennial flowering plant of the genus Campanula. The genus Latin name ("campanula"), meaning small bell, refers to the bell-shape of the flower, while the specific epithet ("medium") means that this plant has intermediate characteristics in respect to other species of the same genus. C. medium were among the first imported flowers grown in colonial American gardens, where they were valued for their showy three-foot stalks of bell-shaped flowers as well as for their edible roots. The flowering period extends from May to July. The hermaphroditic flowers are either self-fertilized or pollinated by insects (e.g., bees and butterflies). The seeds ripen from August to September and are dispersed by gravity alone (Pignatti, 1982; Brandt and Ishimaru, 1998).

Recent studies on the genus Campanula include research on the effect of supplemental light levels and differences in predefined setpoints on the growth development of some Campanula species (Kjaera et al., 2012). In another study, three anthocyanins were isolated from acetic acid extract of the light blue-purple flowers of $C$. medium. A new acylated anthocyanin was elucidated to be delphinidin 3-[6- $O$-( $\alpha$-rhamnopyranosyl)- $\beta$-glucopyranoside]-7$O$-[6-O-(4-O-( $\beta$-glucopyranosyl)- $p$-hydroxybenzoyl)$\beta$-glucopyranoside] as a main anthocyanin, together with two known anthocyanins, violdelphin and delphinidin 3-O-rutinoside-7-O-glucoside as minor anthocyanins (Toki et al., 2009). Also, the seed coat morphology of 10 Campanula species from Turkey was studied using scanning electron microscopy (Akcin, 2009). To the best of our knowledge, no research concerning the chemical composition or antioxidant properties of $C$. medium seeds are yet available.

The trend towards natural ingredients and health promoting products is likely to increase. Non-traditional seeds are being considered because their constituents have unique properties and may augment the supply of functional products. Owing to their medicinal properties and the health-boosting constituents, non-conventional oils are used in the healthcare industry (Ramadan et al., 2009). Apart from triacylglycerols, crude natural oils containa number of bioactive lipid compounds with a very diverse chemical makeup. Among the most interesting are the polar lipids, sterols and fat-soluble vitamins. In this investigation, lipid classes, fatty acids, sterols and tocopherols of C. medium seed oil have been analyzed for the first time. The objective of this investigation was to obtain an informative profile about the chemical profile of $C$. medium seed oil. The results will be important as an indication of the potentially nutraceutical and economic utility of C. medium seeds as a source of edible oils.

\section{MATERIALS AND METHODS}

\subsection{Materials}

C. medium seeds were collected in 2012 from the experimental garden at the Faculty of Agriculture, Zagazig University (Egypt). Neutral lipid (NL) standards were from Sigma (St. Louis, MO, USA). The standards used for the identification of glycolipids (GL) were monogalactosyldiacylglycerol (MGD), digalactosyldiacylglycerol (DGD), cerebrosides (CER), steryl glucoside (SG) and esterified steryl glucoside (ESG), all of which were of plant origin (plant species unknown) and purchased from Biotrend Chemikalien GmbH (Köln, Germany). The standards used for the identification of phospholipids (PL) were phosphatidylserine (PS), phosphatidylethanolamine (PE), phosphatidylinositol (PI) from bovine liver and phosphatidylcholine (PC) from soybean and were purchased from Sigma. The standards used for the characterization of sterols (ST) were purchased from Supelco (Bellefonte, PA, USA). Lanosterol was purchased from Aldrich (St. Louis, MO, USA). $3 \beta$-hydroxy- $5 \alpha$-cholestane (dihydrocholesterol) was used as internal standard (ISTD) and was purchased from Sigma. The standards used for vitamin E $(\alpha-$, $\beta$-, $\gamma$ - and $\delta$-tocopherol) were purchased from Merck (Darmstadt, Germany). Extra virgin olive oil was from a local market (Zagazig, Egypt). The total phenolic compound content in olive oil as determined by the Folin-Ciocalteu at the beginning of the analyses was $337 \mathrm{mg} / \mathrm{kg}$ as gallic acid equivalent.

\subsection{Methods}

\subsubsection{Solvent extraction of total lipids (TL)}

Seeds (moisture content 12\%) were fine powdered using a high-speed mixer, and milled into a fine particle sized (ca. 20-50 $\mu \mathrm{m})$ meal, then subjected to Soxhlet extraction using $n$-hexane for $14 \mathrm{~h}$. The recovered TL were stored at $4{ }^{\circ} \mathrm{C}$ for further analysis. 


\subsubsection{Column chromatography (CC) and thin-layer Chromatography (TLC) of lipid classes}

The TL were separated into different classes by elution with solvents over a glass column $(20 \mathrm{~mm}$ dia $\times 30 \mathrm{~cm})$ packed with a slurry of activated silicic acid (70-230 mesh; Merck, Darmstadt, Germany) in chloroform $(1: 5, \mathrm{w} / \mathrm{v})$. NL were eluted with 3 times the column volume of chloroform. The major portion of GL was eluted with 5-times the column volume of acetone and PL with 4 times the column volume of methanol. By means of TLC on Silica gel $\mathrm{F}_{254}$ plates (thickness $=0.25 \mathrm{~mm}$; Merck, Darmstadt, Germany) a further characterization of GL and PL subclasses was carried out with the following solvent system: chloroform/methanol/ammonia solution $25 \%(65: 25: 4, v / v / v)$. For the characterization of NL subclasses TLC plates were developed using $n$-hexane/diethyl ether/acetic acid (60:40:1, v/v/v). For the detection of the lipids, TLC plates were sprayed with the following agents: for the marking of all lipids with sulfuric acid $(40 \%)$, for the marking of GL with $\alpha$-naphthol/sulfuric acid and for the marking of PL with the molybdate-blue reagent (Kates, 1986; Ramadan et al., 2006). Each spot was identified with lipid standards as well as their reported retention factor $\left(\mathbf{R}_{\mathbf{f}}\right)$ values. Individual bands were visualized under UV light, scraped from the plate and recovered by extraction with chloroform/methanol $(2: 1, \mathrm{v} / \mathrm{v})$.

For the quantitative determination of NL subclasses individual bands were scraped from the plate and recovered by extraction with 10\% methanol in diethyl ether, followed by diethyl ether. The data presented are the average of three gravimetrical determinations. For the quantitative estimation of GL subclasses, the acetone fraction obtained from CC was separated by TLC in the above given solvent system. The silica gel regions with the corresponding GL subclasses were scraped out followed by a hexose measurement at $485 \mathrm{~nm}$ using the phenol/ sulfuric acid in acid-hydrolyzed lipids (Ramadan et al., 2006). The percent distribution of each component was obtained from the hexose values. From the extinction values the quantitative amount was determined and related to their portion of the GL fraction. The determined portion was compared with the amount of TL, which had been separated using $\mathrm{CC}$ in the main lipid fractions. For the determination of PL, the methanol fraction from CC was also separated using TLC in the above given solvent system. After the scraping out of the individual PL subclasses, classes were brought to react with the hydrazine sulfate/sodium molybdate reagent at $100{ }^{\circ} \mathrm{C}$ for $10 \mathrm{~min}$ and espectrophotometrically analyzed at $650 \mathrm{~nm}$. From the obtained extinction values via a calibration chart for phosphorus the amount of PL was calculated. The individual values were compared to the PL fraction (methanol fraction from CC) and to the amount of TL.

\subsubsection{Gas chromatography (GC) analysis of fatty acid methyl esters (FAME)}

The fatty acid compositions of TL, NL, GL and PL were determined using GC as described below. Fatty acids were transesterified into FAME using N-trimethylsulfoniumhydroxide (Macherey-Nagel, Düren, Germany) according to Arens et al. (1994). FAME were determined on a Shimadzu GC-14A equipped with flame ionization detector (FID) and C-R4AX chromatopac integrator (Kyoto, Japan). The flow rate of the carrier gas (helium) was $0.6 \mathrm{~mL} /$ min and the split value was a ratio of 1:40. A sample of $1 \mu \mathrm{L}$ was injected onto a $30 \mathrm{~m} \times 0.25 \mathrm{~mm} \times 0.2 \mu \mathrm{m}$ film thickness Supelco SP ${ }^{\mathrm{TM}}-2380$ (Bellefonte, PA, USA) capillary column. The injector and FID temperature was set at $250{ }^{\circ} \mathrm{C}$. The initial column temperature was $100^{\circ} \mathrm{C}$ programmed at $5^{\circ} \mathrm{C} \mathrm{min}^{-1}$ until $175^{\circ} \mathrm{C}$ and held for $10 \mathrm{~min}$ at $175^{\circ} \mathrm{C}$, then at $8{ }^{\circ} \mathrm{C} \mathrm{min}{ }^{-1}$ until $220{ }^{\circ} \mathrm{C}$ and held for 10 min at $220^{\circ} \mathrm{C}$. A comparison was made between the retention times of the samples with those of authentic FAME standard mixture (ME 19, Sigma, St. Louis, MO, USA; $99 \%$ purity specific for GC) run on the same column under the same conditions to facilitate identification.

\subsubsection{Gas chromatography (GC) analysis of sterols $(S T)$}

The separation of ST was performed after the saponification of oil according to Ramadan et al. (2008). TL (250 mg) were refluxed with $5 \mathrm{~mL}$ of ethanolic potassium hydroxide solution $(6 \%, \mathrm{w} / \mathrm{v})$ and a few anti-bumping granules for $60 \mathrm{~min}$. The unsaponifiables were first extracted 3-times with $10 \mathrm{~mL}$ of petroleum ether. The extracts were combined and washed 3-times with $10 \mathrm{~mL}$ of neutral ethanol/water $(1: 1, \mathrm{v} / \mathrm{v})$, then dried overnight with anhydrous sodium sulfate. The extract was evaporated in a rotary evaporator at $25{ }^{\circ} \mathrm{C}$ under reduced pressure, and then ether was completely evaporated under nitrogen. GC analyses of unsaponifiable residues were carried out using a Mega Series Chromatograph (HRGC 5160, Carlo Erba Strumentazione; Milan, Italy) equipped with an FID. The following GC conditions were used: DB 5 column (JandW scientific; Falsom, CA, USA) packed with $5 \%$ phenylmethylpolysiloxan, $30 \mathrm{~m}$ length, $0.25 \mathrm{~mm}$ i.d., $1.0 \mu \mathrm{m}$ film thickness; carrier gas (helium) flow $0.38 \mathrm{~mL} \mathrm{~min}{ }^{-1}$. Detector and injector were set at $280{ }^{\circ} \mathrm{C}$. The oven temperature was kept constant at $310^{\circ} \mathrm{C}$ and the injected volume was $2 \mu \mathrm{L}$. The repeatability of the analytical procedure was tested and the relative standard deviation of three repeated analyses of a single sample was $<5 \%$. Quantitative analyses were performed with a Shimadzu (C-R6A Chromatopac; Kyoto, Japan) integrator. 


\subsubsection{Normal phase high performance liquid chromatography (NP-HPLC) analysis of tocopherols}

NP-HPLC was selected to avoid extra sample treatment (e.g., saponification) according to Ramadan et al. (2010). The analysis was performed with a solvent delivery LC-9A HPLC (Shimadzu, Kyoto, Japan). The chromatographic system included a model 87.00 variable wavelength detector and a $250 \times 4 \mathrm{~mm}$ i.d. LiChrospher-Si 60 , $5 \mu \mathrm{m}$ column (Knauer, Berlin, Germany). The separation of tocopherols was based on isocratic elution when the solvent flow rate was maintained at $1 \mathrm{~mL}$ $\min ^{-1}$ at a column back-pressure of about $65-70$ bar. The solvent system selected for elution was isooctane/ethyl acetate $(96: 4, \mathrm{v} / \mathrm{v})$ with detection at 295 $\mathrm{nm}$. Twenty $\mu \mathrm{L}$ of the diluted solution of TL in the mobile phase were directly injected into the HPLC. Tocopherols were identified by comparing their retention times with those of authentic standards. Standard solutions were prepared by serial dilution to a concentration of approximately $5 \mathrm{mg} \cdot \mathrm{mL}^{-1}$ of each tocopherol. Standard solutions were prepared from a stock solution which was stored in the dark at $-20{ }^{\circ} \mathrm{C}$. Twenty $\mu \mathrm{L}$ were injected and peak areas were determined to generate standard curve data. All quantification was by peak area using a Shimadzu C-R6A chromatopac integrator (Kyoto, Japan). Standard curves (concentration versus peak area) were calculated from different concentration levels by linear regression. Based on the chromatographic conditions, repeated injections of different concentrations of the tocopherols were made 3 times in the HPLC system. Injections in triplicate were made at each concentration for both standards and samples. All work was carried out under subdued light conditions. All the experiments were repeated at least three times when the variation in any one was routinely less than $5 \%$.

\subsubsection{Analysis of phenolic compounds}

Aliquots of $C$. medium oil and extra virgin olive oil $(2 \mathrm{~g})$ were dissolved in $n$-hexane $(5 \mathrm{~mL})$ and mixed with $10 \mathrm{~mL}$ methanol-water $(80: 20, \mathrm{v} / \mathrm{v})$ in a glass tube for two min in a vortex. After centrifugation at $3000 \mathrm{rpm}$ for $10 \mathrm{~min}$, the hydroalcoholic extracts were separated from the lipid phase using a Pasteur pipet and then combined and concentrated in vacuo at $30^{\circ} \mathrm{C}$ until a syrupy consistency was reached. The lipid residue was re-dissolved in $10 \mathrm{~mL}$ methanolwater $(80: 20, \mathrm{v} / \mathrm{v})$ and the extraction was repeated twice. Hydroalcoholic extracts were re-dissolved in acetonitrile $(15 \mathrm{~mL})$ and the mixture was washed three times with $n$-hexane $(15 \mathrm{~mL}$ each). The purified phenols in acetonitrile were concentrated in vacuo at $30^{\circ} \mathrm{C}$ and then dissolved in methanol for further analysis. Aliquots of phenolic extracts were evaporated to dryness under nitrogen. The residue was re-dissolved in $0.2 \mathrm{~mL}$ water and diluted (1:30) Folin-Ciocalteu's phenol reagent $(1 \mathrm{~mL})$ was added. After $3 \mathrm{~min}, 7.5 \%$ sodium carbonate $(0.8 \mathrm{~mL})$ was added. After a further $30 \mathrm{~min}$, the absorbance was measured at $765 \mathrm{~nm}$ using UV-260 visible recording spectrophotometer (Shimadzu, Kyoto, Japan). Gallic acid was used for the calibration and the results of triplicate analyses are expressed as parts per million of gallic acid.

\subsubsection{Radical scavenging activity ( $R S A)$ of C. medium oil and extra virgin olive oil toward the DPPH radical}

The RSA of $C$. medium oil and olive oil was assayed with DPPH radical previously dissolved in toluene according to Ramadan et al. (2009). A toluene solution of DPPH radicals was freshly prepared at a concentration of $10^{-4} \mathrm{M}$. The radical was stable for more than $2 \mathrm{~h}$ of kinetic assay in the absence of antioxidant compounds. For evaluation, $10 \mathrm{mg}$ of $C$. medium oil or extra virgin olive oil (in $100 \mu \mathrm{L}$ toluene) were mixed with $390 \mu \mathrm{L}$ of the toluene solution of DPPH radicals and the mixture was vortexed for $20 \mathrm{~s}$ at ambient temperature. Against a blank of pure toluene without DPPH, the decrease in absorption at $515 \mathrm{~nm}$ was measured in $1 \mathrm{~cm}$ quartz cells after 1, 30 and 60 min of mixing using a UV-260 visible recording spectrophotometer (Shimadzu, Kyoto, Japan). RSA toward DPPH radicals was estimated from the differences in absorbance of the toluene DPPH solution with or without sample (control) and the inhibition percent was calculated from the following equation:

$\%$ inhibition $=[($ absorbance of control - absorbance of test sample)/ absorbance of control] $\times 100$

\subsubsection{RSA of C. medium oil and extra virgin olive oil toward the galvinoxyl radical}

A Miniscope MS 100 Electron Spin Resonance (ESR) spectrometer (Magnettech $\mathrm{GmbH}$; Berlin, Germany) was used (Ramadan, 2012). The experimental conditions were as follows: measurement at room temperature; microwave power, $6 \mathrm{db}$; centerfield, $3397 \mathrm{G}$, sweep width $83 \mathrm{G}$, receiver gain 10 and modulation amplitude $2000 \mathrm{mG}$. Ten $\mathrm{mg}$ of oils (in $100 \mu \mathrm{L}$ toluene) were allowed to react with $100 \mu \mathrm{L}$ of a toluene solution of galvinoxyl $(0.125 \mathrm{mM})$. The mixture was stirred in a vortex stirrer for $20 \mathrm{~s}$ then transferred to a $50 \mu \mathrm{L}$ micro pipette (Hirschmann Laborgeräte $\mathrm{GmbH}$, Ederstadt, Germany) and the amount of galvinoxyl radical inhibited was measured exactly $60 \mathrm{~s}$ after the addition of the galvinoxyl radical solution. The galvinoxyl signal intensities were evaluated by the peak height of the signals against 
a control. Further ESR spectra have been recorded at intervals of $90 \mathrm{~s}$ for a total incubation time of 60 min. A quantitative estimation of the radical concentration was obtained by evaluating the decrease in the ESR signals in arbitrary units between 1 and 60 min incubation using a KinetikShow 1.06 Software program (Magnettech GmbH; Berlin, Germany). The reproducibility of the measurements was \pm 5 as usual for kinetic parameters.

All experiments were carried out under subdued light conditions. The experiments were repeated at least three times when the variation in any one was routinely less than 5\%. All experimental procedures were performed in triplicate and the mean values ( \pm standard deviation) were given.

\section{RESULTS AND DISCUSSION}

For a crop or plant to be suitable for oil production, it must meet the following criteria; (i) the oil content must reach the minimum for commercially valuable exploitation and (ii) the plant must be suitable for high cultivation (Bockisch, 1998). In this study $C$. medium seeds were found to contain about $9.2 \%$ crude oil. This confirms that $C$. medium seeds could be considered as a good source of oil.

\subsection{Levels of lipid classes and subclasses}

The levels of lipid classes and subclasses present in C. medium oil and the $\mathrm{R}_{\mathrm{f}}$ values of the subclasses are shown in Table 1. Among the TL present in the seeds, the level of NL was the highest ( $c a$. $98.7 \%$ of TL), followed by GL $(0.66 \%$ of TL) and PL $(0.56 \%$ of TL). The subclasses of NL contained triacylglycerol (TAG), free fatty acids (FFA), diacylglycerol (DAG), esterified sterols (STE) and monoacylglycerol (MAG) in decreasing order. Large amounts of TAG were found $(c a .96 .9 \%$ of total NL) followed by FFA ( $c a .1 .01 \%$ of total NL), while DAG and STE were recovered in smaller amounts. The subclasses of GL were sulphoquinovosyldiacylglycerol (SQD), digalactosyldiglycerides (DGD), cerebrosides (CER), sterylglycosides (SG), monogalactosyldiglycerides (MGD) and esterified sterylglycosides (ESG) as presented in Table 1. SG, ESG, CER and DGD were the prevalent components of GL and comprised more than $90 \%$ of the total GL content. The average daily intake of GL in humans was reported to be $140 \mathrm{mg}$ of ESG, $65 \mathrm{mg}$ of SG, $50 \mathrm{mg}$ of CER, $90 \mathrm{mg}$ of MGD and $220 \mathrm{mg}$ of DGD (Sugawara and Miyazawa, 1999). The PL subclasses were separated into four major fractions via TLC (Table 1). The TLC fractions revealed that the main PL subclass was PC followed by PE, PI and PS. About half of the total PL was in PC and $28.4 \%$ was in PE, while PI accounted for $16.1 \%$ of the total PL. PS was measured at lower levels (6.04\% of total PL).

\subsection{Fatty acid profile of seed oil and its lipid classes}

The fatty acid compositions of the TL and lipid classes (NL, GL and PL) are presented in Table 2. Eleven fatty acids were identified in C. medium oil, wherein the analysis of FAME gave the proportion of linoleic (C18:2) followed by oleic $(\mathrm{C} 18: 1)$ as the major fatty acids. Both fatty acids accounted for about $83.1 \%$ of total FAME. Palmitic acid (C16:0) was the main saturated fatty acid $(10.8 \%$ of total FAME) followed by stearic acid (C18:0). Trienes including $\gamma$ - linolenic acid (GLA, C18:3n-6) were also detected but in traces. Furthermore, long-chain fatty acids (lignoceric C24:0 and C20:5 EPA) were estimated in traces. C. medium oil was characterized by a high level of polyunsaturated fatty acids (PUFA), which accounted for $71.4 \%$ of FAME and monounsaturated fatty acids (MUFA) which

TABLE 1. Lipid subclasses $\left(\mathrm{g} \cdot \mathrm{kg}^{-1} \mathrm{TL}\right)$ in C. medium seed oil

\begin{tabular}{|c|c|c|c|c|c|c|c|c|}
\hline $\begin{array}{l}\text { Neutral lipid } \\
\text { Subclass }\end{array}$ & $\begin{array}{c}\mathbf{R}_{f} \\
\text { values } \times 100^{\mathrm{a}}\end{array}$ & $\underset{\mathrm{g} \cdot \mathrm{kg}^{-1}}{\mathrm{TL}}$ & $\begin{array}{l}\text { Glycolipid } \\
\text { Subclass }\end{array}$ & $\begin{array}{c}\mathbf{R}_{f} \\
\text { values } \times 100^{b}\end{array}$ & $\underset{\mathrm{g} \cdot \mathrm{kg}^{-1}}{\mathrm{TL}}$ & $\begin{array}{l}\text { Phospholipid } \\
\text { Subclass }\end{array}$ & $\begin{array}{c}\mathbf{R}_{f} \\
\text { values } \times 100^{\mathrm{b}}\end{array}$ & $\underset{\mathrm{g} \cdot \mathrm{kg}^{-1}}{\mathrm{TL}}$ \\
\hline MAG & 14 & $5.67 \pm 0.07$ & SQD & 6 & $0.40 \pm 0.01$ & PS & 4.7 & $0.33 \pm 0.01$ \\
\hline DAG & 39 & $9.55 \pm 0.11$ & DGD & 17 & $0.88 \pm 0.02$ & PI & 11 & $0.88 \pm 0.06$ \\
\hline FFA & 56 & $10.3 \pm 0.15$ & CER & $29-35$ & $1.00 \pm 0.05$ & PC & 20 & $2.70 \pm 0.05$ \\
\hline TAG & 79 & $926 \pm 3.30$ & SG & 41 & $1.97 \pm 0.05$ & PE & 30 & $1.55 \pm 0.08$ \\
\hline STE & 95 & $3.65 \pm 0.05$ & MGD & 64 & $0.23 \pm 0.03$ & - & - & - \\
\hline- & - & - & ESG & 76 & $1.93 \pm 0.06$ & - & - & - \\
\hline
\end{tabular}

${ }^{\text {a }}$ Solvent system used in TLC development: $n$-hexane/diethyl ether/acetic acid (60:40:1, v/v/v).

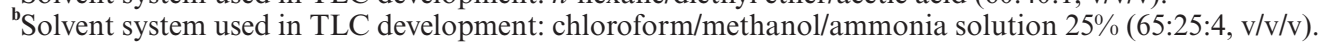

Results are given as the average of triplicate determinations ${ }^{c} \pm$ standard deviation.

Abbreviations: TL, total lipids; MAG, monoacylglycerols; DAG, diacylglycerols; TAG, triacylglycerols; FFA, free fatty acids; STE, sterol esters; SQD, sulphoquinovosyldiacylglycerol; DGD, digalactosyldiacylglycerol; CER, cerebrosides; SG, steryl glucoside; MGD, monogalactosyldiacylglycerol; ESG, esterified steryl glucoside; PS, phosphatidylserine; PI, phosphatidylinositol; PC, phosphatidylcholine; PE, phosphatidylethanolamine. 
TABLE 2. Fatty acid profile of C. medium oil and its lipid classes

\begin{tabular}{lcccc}
\hline & & Neutral lipids & Glycolipids & Phospholipids \\
\cline { 3 - 5 } Fatty acid & Total lipids & \multicolumn{2}{c}{ Relative content (\% weight percentage) } \\
\hline C14:0 & $0.04 \pm 0.06$ & $0.03 \pm 0.05$ & $0.04 \pm 0.05$ & $0.05 \pm 0.07$ \\
C16:0 & $10.8 \pm 0.55$ & $10.6 \pm 0.47$ & $10.9 \pm 0.50$ & $11.1 \pm 0.46$ \\
C16:1 & $0.29 \pm 0.09$ & $0.30 \pm 0.08$ & $0.27 \pm 0.08$ & $0.28 \pm 0.07$ \\
C18:0 & $3.43 \pm 0.22$ & $3.36 \pm 0.26$ & $3.55 \pm 0.24$ & $3.69 \pm 0.25$ \\
C18:1n-9 & $13.4 \pm 1.04$ & $13.5 \pm 1.01$ & $13.4 \pm 0.99$ & $13.4 \pm 1.02$ \\
C18:2n-6 & $70.9 \pm 3.04$ & $71.0 \pm 3.05$ & $70.7 \pm 3.11$ & $70.3 \pm 2.99$ \\
C20:0 & $0.38 \pm 0.05$ & $0.35 \pm 0.03$ & $0.39 \pm 0.09$ & $0.44 \pm 0.05$ \\
C18:3n-3 & ND & ND & ND & ND \\
C18:3n-6 & $0.20 \pm 0.02$ & $0.26 \pm 0.05$ & $0.20 \pm 0.03$ & $0.20 \pm 0.01$ \\
C20:2 & $0.16 \pm 0.02$ & $0.18 \pm 0.05$ & $0.14 \pm 0.05$ & $0.12 \pm 0.03$ \\
C22:1n-9 & ND & ND & ND & ND \\
C20:3 & ND & ND & ND & ND \\
C24:0 & $0.23 \pm 0.02$ & $0.20 \pm 0.03$ & $0.26 \pm 0.04$ & $0.28 \pm 0.04$ \\
C20:5 EPA & $0.17 \pm 0.02$ & $0.20 \pm 0.04$ & $0.15 \pm 0.03$ & $0.13 \pm 0.05$ \\
C22:6 DHA & ND & ND & ND & ND \\
Total SFA & 14.88 & 14.54 & 15.14 & 15.56 \\
Total MUFA & 13.69 & 13.82 & 13.67 & 13.69 \\
Total PUFA & 71.43 & 71.64 & 71.19 & 70.75 \\
\hline
\end{tabular}

${ }^{\mathrm{a}}$ Not detected.

Results are given as the average of triplicate determinations \pm standard deviation.

accounted for $c a .13 .7 \%$ of FAME. MUFA have been shown to lower "bad" LDL cholesterol (low density lipoproteins) yet retain "good" HDL cholesterol (high density lipoproteins). This is in fact the major benefit of olive oil over the highly polyunsaturated edible oils, wherein PUFA reduce both the "bad" as well as the "good" serum cholesterol levels in the blood (Ramadan et al., 2010). Fatty acids in NL and polar lipids were not significantly different from each other, wherein linoleic followed by oleic, palmitic and stearic were the main fatty acids. The ratio of unsaturated fatty acids to saturated fatty acids, however, was higher in neutral fractions than in the corresponding polar fractions (GL and PL). Concerning saturated fatty acids (especially palmitic and stearic), GL resembled PL in the higher contents of saturates, while saturated fatty acids were detected in relatively lower levels in the corresponding NL.

From the results, it could be concluded the fatty acid profile of $C$. medium oil shows the lipids as a good source of the nutritionally essential PUFA and oleic acid. Interest in PUFA as healthpromoting nutrients has expanded in recent years. A rapidly growing literature illustrates the benefits of PUFA in alleviating cardiovascular, inflammatory, heart diseases, atherosclerosis, autoimmune disorder, diabetes and other diseases (Riemersma, 2001). The fatty acid composition and high amounts of
PUFA make the $C$. medium seed oil a special component for nutritional applications. However, as there is no information available about the food use of $C$. medium plant and seeds, the safety of its seed oil shall be investigated before promoting the use of the oil as an ingredient for foods or food supplements.

\subsection{Sterol (ST) composition}

The Amounts of ST in oils are used for an oil's identification, oil derivatives and for the determination of the oil quality. The concentration of ST has been reported to be little affected by environmental factors or by the cultivation of new breeding lines (Homberg, 1991; Ramadan et al., 2006). C. medium oil is characterized by high levels of unsaponifiables $\left(7 \mathrm{~g} \cdot \mathrm{kg}^{-1} \mathrm{TL}\right)$. Seven sterol compounds were detected, wherein the sterol marker was $\beta$-sitosterol which comprised $c a .52 \%$ of the total ST content (Table 3). The next major components were $\Delta 7$-avenasterol and stigmasterol. These three major components accounted for more than $96 \%$ of the total ST. Other components, e.g., $\Delta 5$-avenasterol, lanosterol, $\Delta 7$-stigmastenol and sitostanol were found in lower levels. Brassicasterol, campesterol and $\Delta 5,24$-stigmastadinol were not detected in the $C$. medium unsaponifiables. Among the different sterols, sitosterol has been most intensively 
investigated with respect to its physiological effects in humans. Many useful and health-promoting effects have been shown for the sitosterol (Yang et al., 2001). Recently, phytosterols have been added to vegetable oils as an example of a successful functional food.

\subsection{Tocopherols profile}

Tocopherols are the major lipid-soluble, membrane-localized antioxidants in humans and vitamin E deficiency causes defects in the developing nervous system of children and hemolysis in adults. Eipdemiologic studies suggest that people with lower vitamin $E$ and other antioxidant intake may be at increased risk for certain types of cancer and atherosclerosis (Gey et al., 1991; Ramadan et al., 2006). Moreover, tocopherols in vegetable oils are believed to protect PUFA from peroxidation. Data about the qualitative and quantitative composition of tocopherols are summarized in Table 3. All tocopherols were present, wherein $\beta$-tocopherol constituted $42.5 \%$ of the total analytes followed be $\gamma$-tocopherol ( $c a .41 .3 \%$ of total tocopherols). $\alpha$ and $\gamma$-tocopherols were measured in low levels. $\alpha$ and $\gamma$-tocopherols proved to be the main tocopherols in vegetable oils and fats. $\gamma$-tocopherol occurred in high concentrations in camelina, linseed, coldpressed rapeseed and corn oil (Schwarz et al., 2008). $\alpha$-tocopherol is the most efficient antioxidant of tocopherols, while $\beta$-tocopherol has $25-50 \%$ of the antioxidative activity of $\alpha$-tocopherol, and

TABLE 3. Levels of sterols and tocopherols in C. medium seed oil

\begin{tabular}{lcc}
\hline Compound & $\mathbf{m g} \cdot \mathbf{k g}^{-\mathbf{1}}$ & $\%$ \\
\hline Brassicasterol & $\mathrm{Nd}^{\mathrm{a}}$ & 0.0 \\
Campesterol & $110 \pm 0.09$ & 2.5 \\
Stigmasterol & $500 \pm 0.08$ & 10.9 \\
Lanosterol & $170 \pm 0.02$ & 3.6 \\
$\beta$-Sitosterol & $2410 \pm 0.33$ & 52.0 \\
$\Delta$ 5-Avenasterol & $490 \pm 0.09$ & 10.6 \\
Sitostanol & $390 \pm 0.07$ & 8.3 \\
$\Delta 5,24-$ Stigmastadinol & $\mathrm{Nd}$ & 0.0 \\
$\Delta$ 7-Stigmastenol & $\mathrm{Nd}$ & 0.0 \\
$\Delta$ 7-Avenasterol & $560 \pm 0.23$ & 12.1 \\
$\alpha$-Tocopherol & $180 \pm 0.06$ & 15.9 \\
$\beta$-Tocopherol & $491 \pm 0.09$ & 42.5 \\
$\gamma$-Tocopherol & $477 \pm 0.11$ & 41.3 \\
$\delta$-Tocopherol & $3.0 \pm 0.001$ & 0.3 \\
\hline
\end{tabular}

${ }^{\mathrm{a}}$ Not detected.

Resultsaregiven as the average of triplicatedeterminations \pm standard deviation. $\gamma$-isomer 10-35\% (Kallio et al., 2002). Despite agreement that $\alpha$-tocopherol is the most efficient antioxidant in vivo, studies indicate a considerable discrepancy in its absolute and relative antioxidant effectiveness in vitro, especially when compared to $\gamma$-tocopherol (Kamal-Eldin and Appelqvist, 1996). Levels of tocopherols detected in C. medium oil may contribute to the stability of the oil toward oxidation.

\subsection{RSA of C. medium oil in comparison with extra virgin olive oil}

Interest has increased in the free radical theory of the cause of disease, particularly in vascular diseases and cancer. These developments have led to the investigation on the role of antioxidants in disease protection. A free radical is defined as any chemical species that has one or more unpaired electron. Antioxidants quench those radicals and if the supply of antioxidants is inadequate, a chain reaction takes place that may lead to damaged tissue. Previous study on the radical scavenging properties of vegetable oils had used different solvents to dissolve the oils and the free radicals. Thus, the results were difficult to compare because the reactions occurred under different conditions. In contrast, a simple experiment (Ramadan et al., 2010) has been performed using the same solvent (toluene) to dissolve the oil samples and the free radicals.

A)
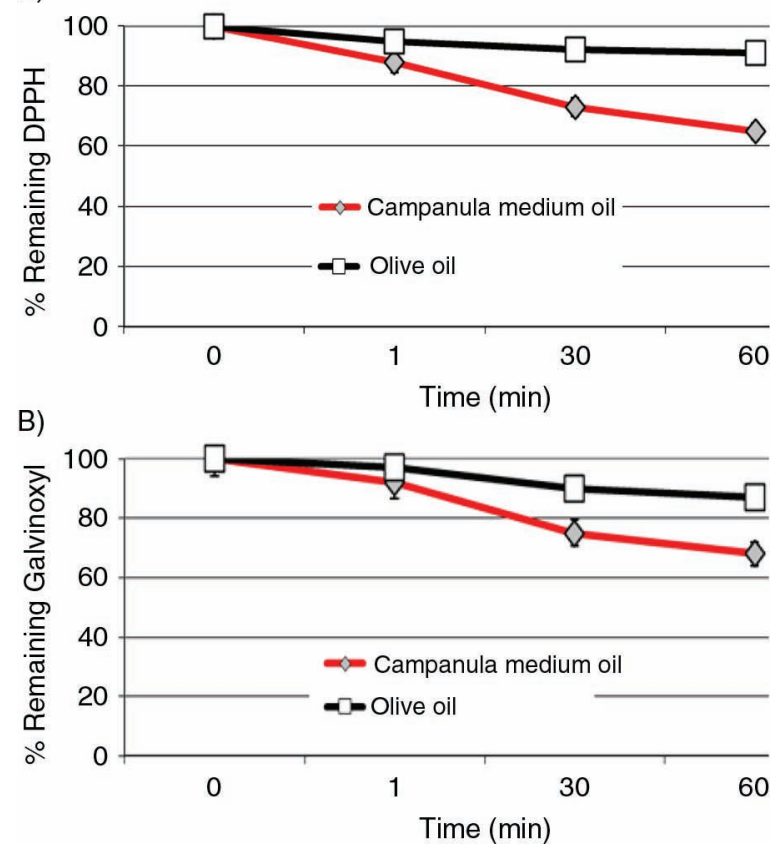

FIGURE 1. Antiradical effect of C. medium seed oil and extra virgin olive oil on DPPH radicals (A) as measured by changes in absorbance values at $515 \mathrm{~nm}$ and on galvinoxyl radicals (B) as recorded by ESR. 
This allowed us to characterize and compare the RSA of all samples under the same conditions.

Apart from the fatty acid profile, the stability of vegetable oils depends on the presence of minor fatsoluble bioactives and the initial amount of hydroperoxides. RSA of the C. medium oil and extra virgin olive oil (as a standard crude oil with respective high levels of nutritive antioxidants and bioactives) were compared using stable DPPH and galvinoxyl radicals. Figure 1 shows that $C$. medium oil had higher RSA values than olive oil. After 60 min incubation, $35 \%$ of DPPH radicals were quenched by $C$. medium oil, while olive oil was able to quench $9 \%$ (Figure 1A). ESR measurements showed the same pattern, wherein $C$. medium oil quenched $32 \%$ galvinoxyl radicals and olive oil quenched $13 \%$ after 60 min of reaction (Figure 1B).

C. medium oil and olive oil have different patterns of fatty acid and lipid-soluble bioactives. $C$. medium oil was characterized by higher phenolic content $\left(466 \mathrm{mg} \cdot \mathrm{kg}^{-1}\right)$ than extra virgin olive oil ( $337 \mathrm{mg} \cdot \mathrm{kg}^{-1}$ ). It could be said that the RSA of oils can be interpreted as the combined action of different endogenous antioxidants. However, when polar fractions (mainly polar lipids and phenolics) are found in high levels, strong RSA of these components can be expected (Ramadan et al., 2010). The stronger antiradical action of $C$. medium oil compared to olive oil may be due to (i) the differences in levels and composition of polar lipids and unsaponifiables (phytosterols and tocols) (ii) the diversity in structural characteristics of potential antioxidants present, (iii) a synergism of polar lipids with other components present, and (iv) different kinetic behaviors of potential antioxidants.

\section{CONCLUSIONS}

Knowledge concerning the composition and properties of $C$. medium seeds would assist in efforts for industrial, nutritional and medical application of this plant. It is difficult to find data about the bioactive lipids and antioxidant compounds of C. medium seed oil in the literature. It could be concluded that C. medium seeds give considerable oil yield and the oil seems to be a good source of essential fatty acids and lipid-soluble bioactives. The high linoleic and oleic acid content makes the oil nutritionally valuable. Tocopherols and sterols at the level estimated may be of nutritional importance in the application of the seed oil. C. medium seeds could be nutritionally considered as a new non-conventional supply for pharmaceutical industries and edible purposes.

\section{REFERENCES}

Akcin TA. 2009. Seed coat morphology of some Turkish Campanula (Campanulaceae) species and its systematic implications. Biologia 64, 1089-1094. http://dx.doi. org/10.2478/s11756-009-0177-5
Arens M, Schulte E, Weber K. 1994. Fettsäuremethylester, Umesterung mit Trimethylsulfoniumhydroxid (Schnellverfahren). Fat Sci. Technol. 96, 67-68.

Bockisch M. 1998. Vegetable fats and oils, In M. Bockisch, Fats and Oils Handbook (pp. 174-344). Champaign: AOCS Press.

Brandt K. Ishimaru K. 1998. Campanula (Bellflower) Species: In Vitro Culture, Micropropagation, and the Production of Anthocyanins, Polyacetylenes, and Other Secondary Metabolites. In Medicinal and Aromatic Plants X, ed by Y. P. S. Bajaj, Springer-Verlag Berlin, pp. 45-66.

Gey KF, Puska P, Jordan P, Moser UK. 1991. Inverse correlation between plasma vitamin $\mathrm{E}$ and mortality from ischemic heart disease in cross-cultural epidemiology. Amer. J. Clin. Nutr. 53, 3245-3265.

Homberg E. 1991. Sterinanalyse als Mittel zum Nachweis von Vermischungen und Verfälschungen. Fat Sci. Technol. 93, 516-517.

Kallio H, Yang B, Peippo P, Tahvonen R, Pan R. 2002. Triacylglycerols, glycerophospholipids, tocopherols and tocotrienols in berries and seeds of two subspecies (ssp. sinensis and mongolica) of Sea buckthorn (Hippophaë rhamnoides). J. Agric. Food Chem. 50, 3004-3009. http:// dx.doi.org/10.1021/jf011556o.

Kamal-Eldin A, Appelqvist LA. 1996. The chemistry and antioxidant properties of tocopherols and tocotrienols. Lipids 31, 671-701 http://dx doi. org/10.1007/BF02522884.

Kates M. 1986. Techniques of lipidology: isolation, analysis, and identification of lipids. Ed. by Kates M. Elsevier (USA).

Kjaera KH, Ottosen CO, Jørgensen BN. 2012. Timing growth and development of Campanula by daily light integral and supplemental light level in a cost-efficient light control system. Sci. Hort. 143, 189-196. http://dx.doi.org/10.1016/j. scienta.2012.06.026.

Morton JF. 1977. Major Medicinal Plants, Botany, Culture and Uses, Charles C. Thomas Publisher, Springfield, U.S.A.

Okinaka Y, Shimada Y, Nakano-Shimada R, Ohbayashi M, Kiyokawa S, Kikuchi Y. 2003. Selective accumulation of delphinidin derivatives in tobacco using a putative flavonoid $3^{\prime}, 5^{\prime}$-hydroxylase cDNA from Campanula medium. Biosci. Biotechnol. Biochem. 67, 161-165. http://dx.doi. org/10.1271/bbb.67.161.

Pignatti S. 1982. Flora d'Italia - Edagricole-, Vol. II, pp. 682.

Ramadan MF. 2012. Antioxidant characteristics of phenolipids (quercetin-enriched lecithin) in lipid matrices. Ind. Crops Prod. 36, 363-369. http://dx.doi.org/10.1016/j. indcrop.2011.10.008.

Ramadan MF, Amer, MMA, Awad A. 2008. Coriander (Coriandrum sativum L.) seed oil improves plasma lipid profile in rats fed diet containing cholesterol. Eur. Food Res. Technol. 227, 1173-1182. http://dx.doi.org/10.1007/ s00217-008-0833-y.

Ramadan MF, Kinni SG, Rajanna LN, Seetharam YN, Seshagiri M, Mörsel JT. 2009. Fatty acids, bioactive lipids and radical scavenging activity of Celastrus paniculatus Willd. seed oil. Sci. Hort. 123, 104-109. http://dx.doi.org/10.1016/j. scienta.2009.07.008.

Ramadan MF, Kinni SG, Seshagiri M, Mörsel JT. 2010. Fatsoluble bioactives, fatty acid profile and radical scavenging activity of Semecarpus anacardium seed oil. J. Am. Oil Chem. Soc. 87, 885-894. http://dx.doi.org/10.1007/ s11746-010-1567-0.

Ramadan MF, Sharanabasappa G, Seetharam YN, Seshagiri M, Moersel JT. 2006. Profile and levels of fatty acids and bioactive constituents in mahua butter from fruit-seeds of Buttercup tree [Madhuca longifolia (Koenig)]. Eur. Food Res. Technol. 222, 710-718. http://dx.doi.org/10.1007/ s00217-005-0155-2.

Rameau JC, Mansion D, Dume G, 1989. Flore Forestiere Francaise, Guide Ecologique illustre, 1, Paris.

Riemersma RA. 2001. The Demise of The n-6 to n-3 Fatty Acid Ratio? A Dossier. Eur. J. Lipid Sci. Technol. 103, 372-373. http://dx.doi.org/10.1002/1438-9312(200106)103:6<372:: AID-EJLT372>3.0.CO;2-3.

Schwartz H, Ollilainen V, Piironen V, Lampi AM. 2008. Tocopherol, tocotrienol and plant sterol contents of vegetable oils and industrial fats. J. Food Comp. Anal. 21, 152161. http://dx.doi.org/10.1016/j.jfca.2007.07.012. 
Sugawara T, Miyazawa T. 1999. Separation and determination of glycolipids from edible plant by high-performance liquid chromatography and evaporative light-scattering detection. Lipids 34, 1231-1237. http://dx.doi.org/10.1007/ s11745-999-0476-3.

Toki K, Saito N, Nishi H, Tatsuzawa F, Shigihara A, Honda T. 2009. 7-Acylated anthocyanins with $p$-hydroxybenzoic acid in the flowers of Campanula medium. Heterocycles 77 , 401-408. http://dx.doi.org/10.3987/COM-08-S(F)32.

Touafek O, Kabouche Z, Brouard I, Bermejo JB. 2011. Flavonoides of Campanula alata and their antioxidant activity. Chem. Nat. Comp. 46, 968-970. http://dx.doi. org/10.1007/s10600-011-9799-2.

Yang B, Karlsson RM, Oksman PH, Kallio HP. 2001. Phytosterols in sea buckthorn (Hippophaë rhamnoides L.) berries: Identification and effects of different origins and harvesting times. J. Agric. Food Chem. 49, 5620-5629. http://dx.doi.org/10.1021/jf001059s.

Yildırım H. 2013. Campanula mugeana sp. nov. (Campanulaceae) from western Anatolia, Turkey. Nordic J. Botany. 31, 419-425. http://dx.doi.org/10.1111/j.1756-1051.2012. 01786.x. 